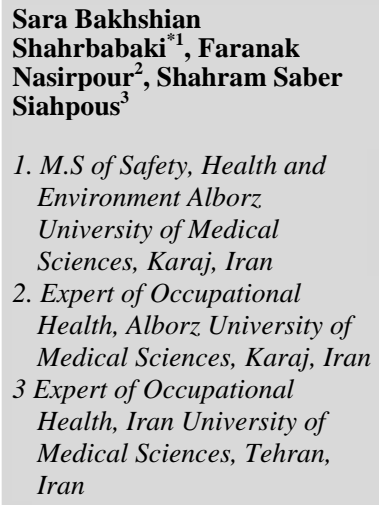

\section{Hearing loss Assessment of Welders Who Referred to Health Center of Fardis}

Received: 30 Jul. 2016; Accepted: 27 Jan. 2018

\section{Abstract}

Introduction: Noise is one of the most common physical harmful agent in the work places with different severity in almost all industries. The noise higher than the standard level can be a potential source for human injuries. The aim of this study was to evaluate noise induce hearing loss among welders.

Materials and Methods: This cross - sectional study was done in 2013 to 2014 on the welders who referred to occupational medicine centers of Shohadaye Fardis to do occupational medicine checkup. Audiometric test was done in acoustics room for both ear and after data collection, statistical analysis was performed using SPSS software (version 22).

Results: The results showed that among 54 welders ( $5.17 \%$ of all referred persons), 18 persons $(33.3 \%)$ has hearing problems, 36 persons $(66.7 \%)$ of persons were healthy. among welders with hearing loss, 6 persons (33\%) had unilateral NIHL and 11 persons $(66 \%)$ had a bilateral NIHL. hearing loss was more in $6000 \mathrm{~Hz}$ frequency in the left ear.

Conclusions: Research showed that welders are prone to hearing loss and requires corrective and preventive actions in order to control their hearing system damage.

Keywords: Noise, Hearing Loss, NIHL 


\section{بررسى افت شنوايى كاركران جوشكار مراجعه كننده به مركز بهداشتى درمانى شهداى فرديس جوسار مراجئ}

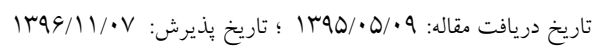

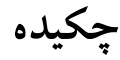

مقدمه: سروصدا يكى از شايع ترين عوامل فيزيكى موجود در محيط كار است كه بـا شــتهــاى مختلـف تقريبـاً در تمـام

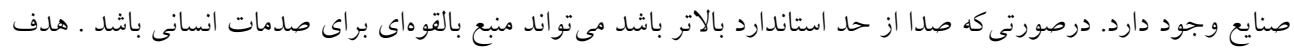

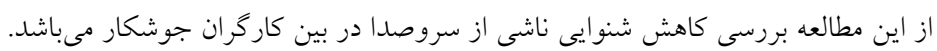

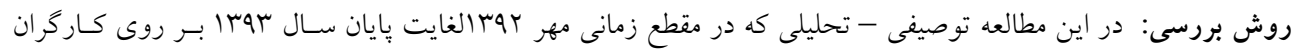

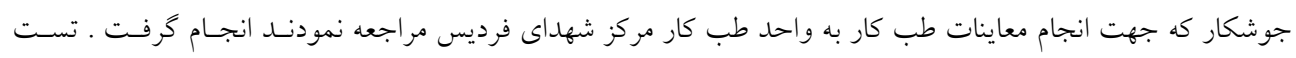

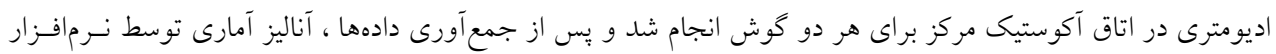
SPSS

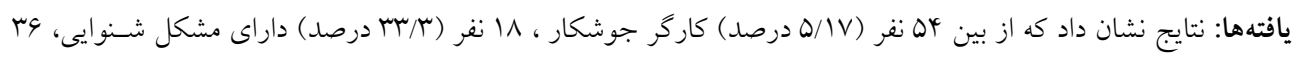

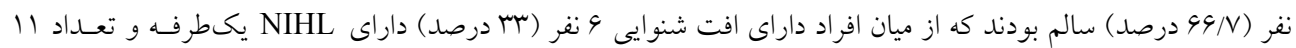

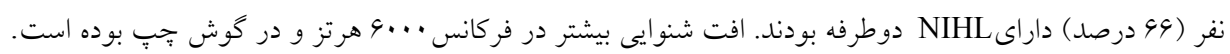

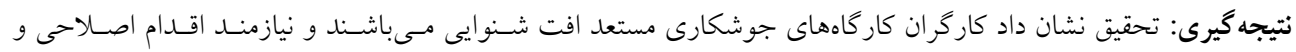

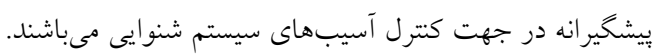

كلمات كليدى: سروصدا، افت شنوايى، NIHL

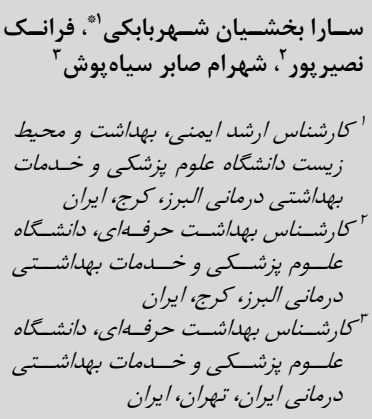
درمانى /يران، تهران، ايران 


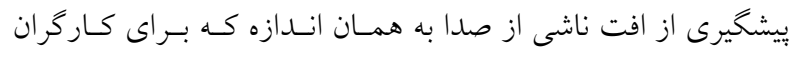

مفيد است براى كارفرما نيز سودمند مىباشد جر اكه كارفرمايـان نيـز از فوايد كاهش هزينه هاى بزشكى و يرداخت غرامت به كاركر سود

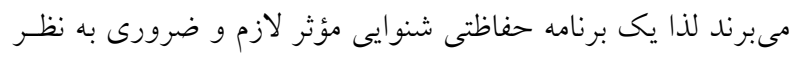

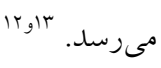

\section{مواد و روشها}

روش مطالعه توصيفى - تحليلى مىباشد ـ جامعـه موردمطالعه.

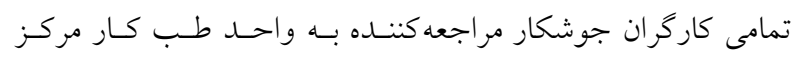

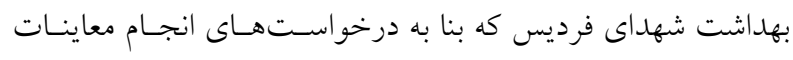

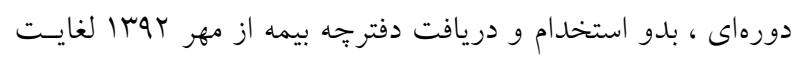

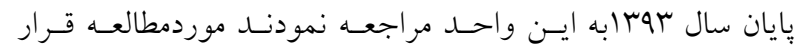

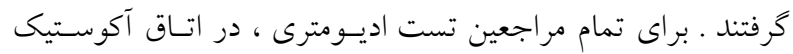

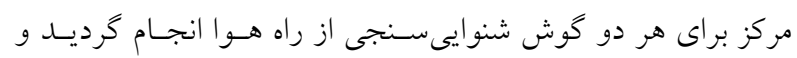

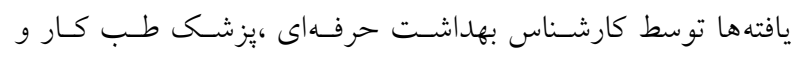

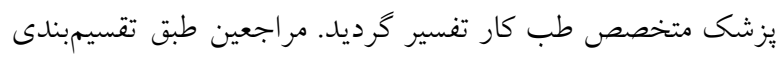

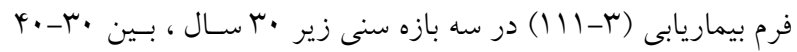

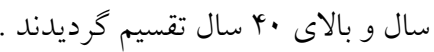

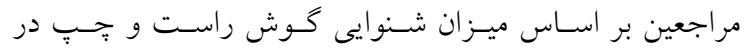

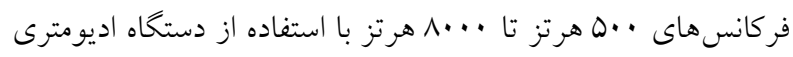

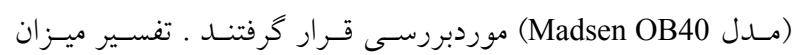

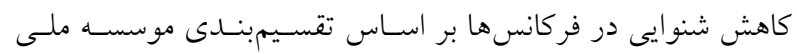

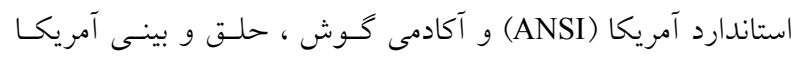

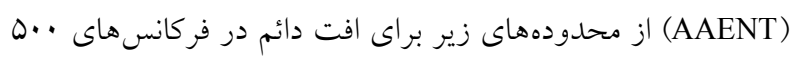
تا ل ا...1 استفاده شد:

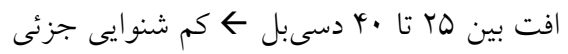
افت بين الب تا هه دسىبل ٪ كم شنوايى ملايم افت بين وه تا • V دسىبل ٪ كم شنوايى متوسط افت بين VI تا •و دسىبل ک كم شنوايى شديد افت بالاى •9 دسىبل † ناشنو ايى يا كرى دائم

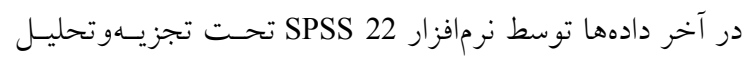
قرار كرفت. در طى انجام اين مطالعه به اصول تعهدنامـه هلسـينكى يايبند بوده و هيج گونه هزينه اضافى از افراد گرفته نشده است.
سروصدا يكى از شايعترين عوامل فيزيكى موجود در محيط كار

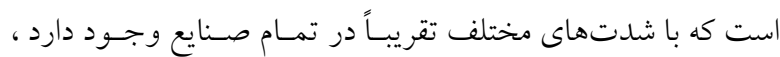

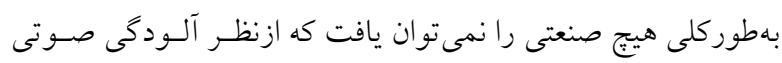

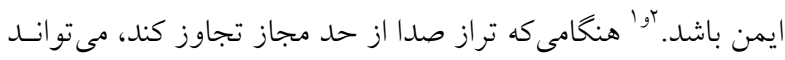

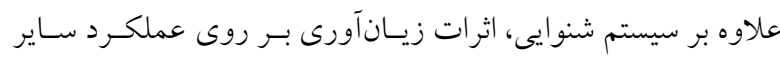

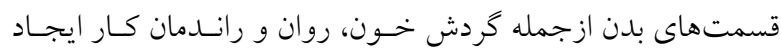

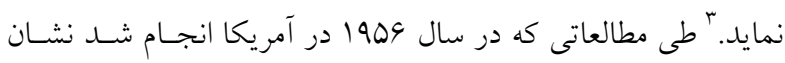

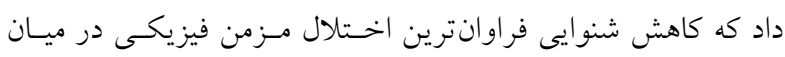

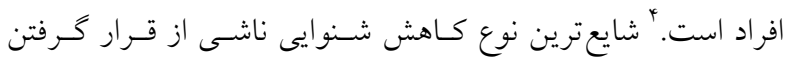

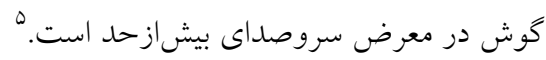

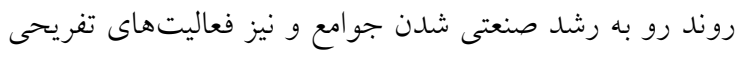

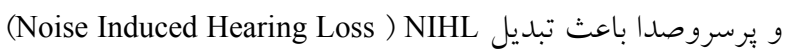

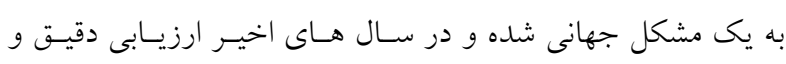

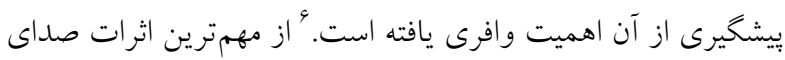

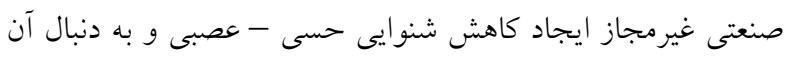
وزوز كوش است. سروصدا هاى محيط كار باعث آسيب حلزون كوش داخلى و و به آنه

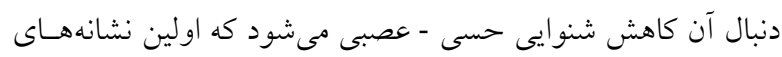

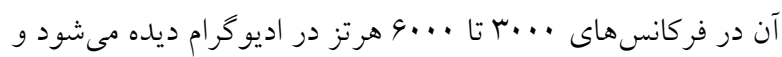

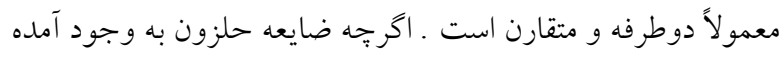

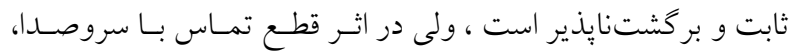

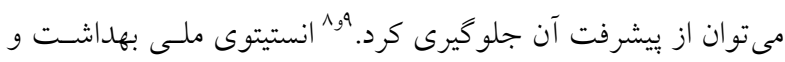

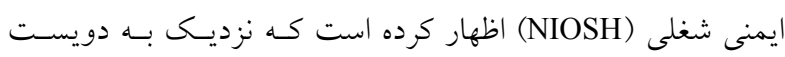

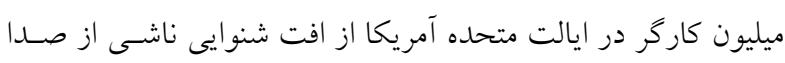
خسارتديدهاند و طبق بررسىهاى NIOSH (NIHL) كل جمعيت كارگر ان در محيطهايى به كار گرفته مىشوند كـه تـراز

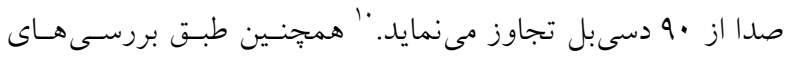

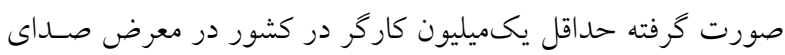

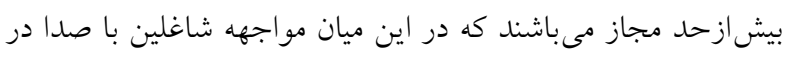

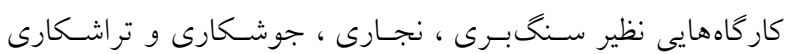
قابل توجه مىباشد." خوشبختانه افت شنوايى شغلى هميشـهـ قابـل ييشـيرى اسـت. 


$$
\text { درصد) بوده است. }
$$

\section{يافته ها}

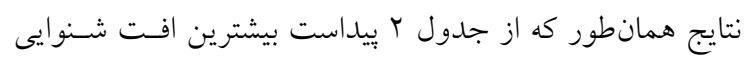

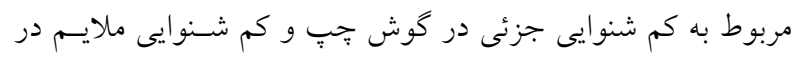

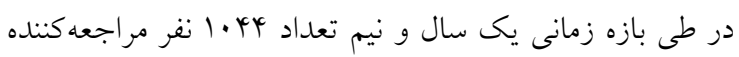

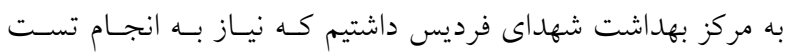

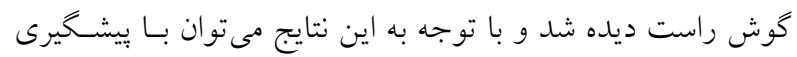

$$
\text { از افت شنوايى جلوى بيشرفت بيمارى را كرفت . }
$$

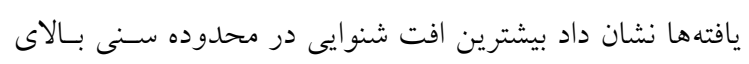
r r.

$$
\text { شنوايى مىباشد (جدول شماره ؟). }
$$

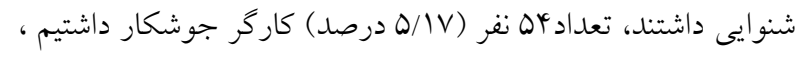

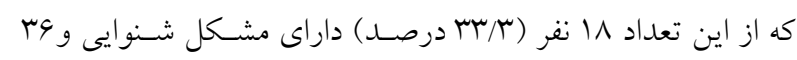
نفر (99/V درصد) سالم بودند كه از ميان افراد داراى كاهش شنوايى نهر

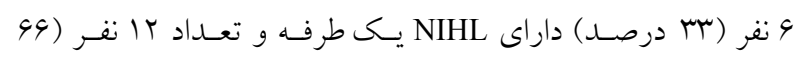
درصد) داراى NIHL دوطرفه بودند. بر اساس نتايج بـهدسـت آمــه

\begin{tabular}{|c|c|c|c|c|c|c|c|}
\hline$\wedge \cdots$ & $9 \cdots$ & $f \ldots$ & $\mu \ldots$ & $r \ldots$ & $1 \cdots$ & $0 .$. & عنوان \\
\hline 1. & 10 & 14 & 9 & 9 & 1 & 1 & تعداد نفرات \\
\hline$\Delta Q / \Delta$ & $\Lambda \mu / r$ & VV/V & 0. & 愐 & $\Delta / \Delta$ & $0 / 0$ & درصد مواجهه \\
\hline
\end{tabular}

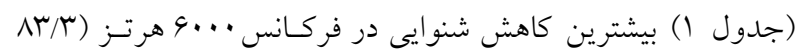

جدول ا: درصد كاهش شنوايى برحسب فركانس

\begin{tabular}{|c|c|c|c|c|c|c|c|c|}
\hline \multicolumn{2}{|c|}{ كم شنوايى شديد } & \multicolumn{2}{|c|}{ كم شنوايى متوسط } & \multicolumn{2}{|c|}{ كم شنوايى ملايم } & \multicolumn{2}{|c|}{ كم شنوايى جزئى } & \multirow{2}{*}{ عنوان } \\
\hline كوش جִ & كوش راست & گوش جِ & كوش راست & كوش جִب & كوش راست & كوش جِب & گوش راست & \\
\hline$r$ & $r$ & $r$ & $r$ & $r$ & 9 & 9 & $r$ & تعداد \\
\hline $19 / 9$ & $19 / 9$ & $T Y / T$ & $19 / 9$ & $11 / 1$ & r & r & $19 / 9$ & درصد \\
\hline
\end{tabular}

جدول r: فراوانى كاهش شنوايى

\begin{tabular}{|c|c|c|c|c|c|}
\hline \multirow[b]{2}{*}{ افت كل } & \multicolumn{4}{|c|}{ NIHL } & \multirow[b]{2}{*}{ محدوده سنى } \\
\hline & كم شنوايى شديد & كم شنوايى متوسط & كم شنوايى ملايم & كم شنوايى جزئى & \\
\hline$r Y / l$ & - & - & $0 / 0$ & $19 / 9$ & زير ·r سال \\
\hline rN/V & - & $\Delta / \Delta$ & $19 / 9$ & $19 / 9$ & بين •r تا •r سال \\
\hline $94 / r$ & $\mathrm{~V} / \mathrm{V}$ & $19 / 9$ & - & - & بالاى •r سال \\
\hline
\end{tabular}

جدول بم: ارتباط بين محدوده سنى و افت شنوايى در بين كاركران جوشكار 


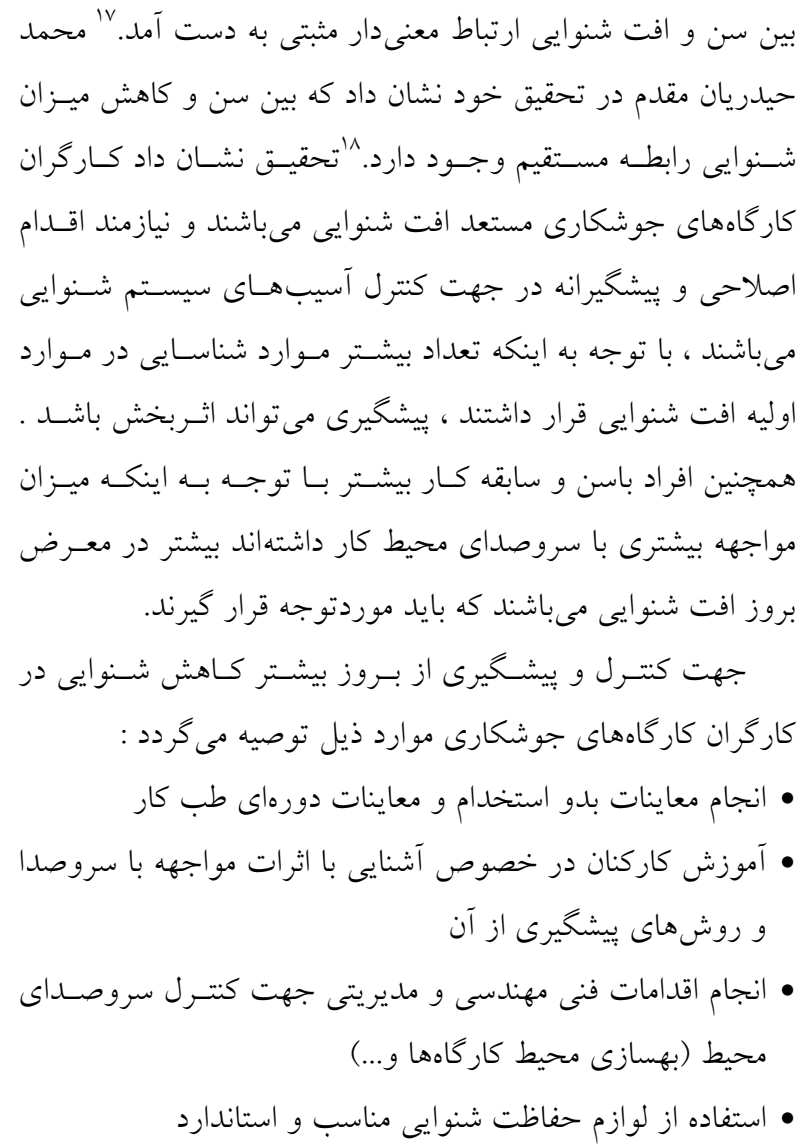

\section{References}

1. Ferrite S, Santana V. Joint effects of smoking, noise exposure and age on hearing loss. Occupational Medicine 2005; 55: 48-53.

2. Mirmohammadi J, Baba Haji Meibodi F, Nourani F. Investigating the hearing tolerance in the workers of the tile factory complex of Meybod. Journal of Shahid Sadoughi University of Medical Sciences.2008; 16(1):813.[In Persian]

3. Halvani G, Zare M, Barkhourdari A. Investigating relation noise and hearing loss in workers of textile factories of Taban of Yazd. Journal of Medical Science of Birjand University 2009; 15(4): 69-75.[In Persian]

4. Alberti PW, Ruben RJ. Otologic Medicine \& Surgery, Basic Audiologic Evaluation. 1st ed. New York, Churchill Livingston, 1988; PP: 365-395.

5. Ballenger JJ, James B, Snow J. Otolaryngology Head and Neck Surgery: Occupational Hearing Loss. 5th ed . Baltimore, Williams \& Wilkins, 1996; P: 1087-1101.

6. Dobie RA. Noise-induced Hearing loss. In: Bailey BJ, Calhoun KH, editors. Head and Neck surgery-

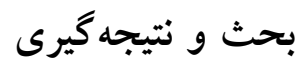

$$
\begin{aligned}
& \text { از نتايج اين طرح جنين برمى آيد كه بيشترين مورد افت شنوايى }
\end{aligned}
$$

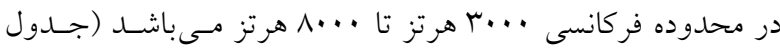

$$
\begin{aligned}
& \text { شماره () ، كه بامطالعه دكتر سيد عباس صفوى نائينى و همكارانش } \\
& \text { همخوانى دارد. }
\end{aligned}
$$$$
\text { همجنين با توجه به نتايج جدول شماره Y ، بيشترين مورد افـت }
$$$$
\text { شنوايى مربوط به كم شنوايى جزئى(كاهش بسين }
$$

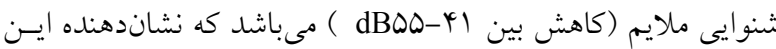$$
\text { مى باشد كه افت شنوايى در مراحل اوليه خود مىباشد . با توجـهـ بــه }
$$$$
\text { اينكه در ابتدا افت شنوايى در فر كانسهاى بـالا ايجـاد مسى كـردد و }
$$

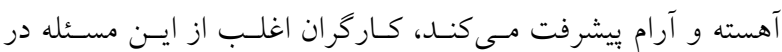$$
\text { مر احل اوليه شكايت نمى كنند. هاتحقيق نشان داد كه بيشـترين مـوارد }
$$

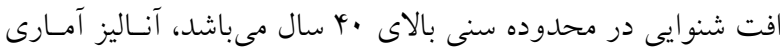

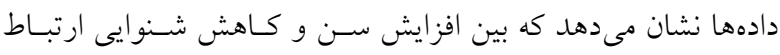$$
\text { معنىدارى وجود دارد. جون با افزايش سن ميزان سابقه كار و ميـزان }
$$

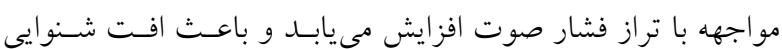$$
\text { بيشـتر مسىشـود كـه بامطالعـه رضـا تاجيـك و همكــاران مطابقــت }
$$

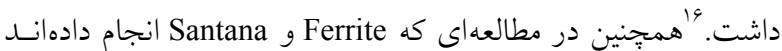

Otolaryngology. Philadelphia: Lippincott Williams\& Wilkins; 2001. p. 1883-90.

7. Passchier Vermeer W. Passchier WF. Noise exposure and public health. Environ Health Perspect 2000 Mar;108Suppl [;123-31. Review.

8. Sliwińska-Kowalska M, Dudarewicz A, Kotyło P, Zamysłowska-Szmytke E, Pawlaczykłuszczyńska M, Gajda-Szadkowska A. Individual susceptibility to noise induced hearing loss :choosing an optimal method of retrospective classification of workers in to noisesusceptible and noise-resistant groups. Occupational Medicine and Environment Health 2006; 19: 235-45.

9. Sharon G, Kujawa M, Chales L. Acceleration of agerelated hearing loss by early noise exposure: evidence of a misspent youth. The Journal of Neuroscience 2006; 26: 2115-23.

10. Salmivali A. Military audiological aspect in noise induced hearing loss. Acta otolaryngol suppl. 1998; 360: 96-102. 
11. Nekohi N, et al. Noise pollution in small Workshops Covered health centers Bojnurd. Journal of North Khorasan University of Medical Sciences 2013;5(Student Research Committe Supplementary):925.

12. Ghorbani Shahn F. Noise induced hearing loss and its relationship with dose and exposure length. The journal of Gazvin University oh medical sciences. 2006; 10(38): 84-88.[In Persian]

13. Dobie R . economic comparison for hearing loss . Occup Med State Rev . 1995; 10 : 663-668.

Safavi Naieni S, et al. Workers hearing status assessment in noisy workshops of Tehran Azmayesh Factory. Research in medical (Researching journal of medical college) Shahid beheshti university of medical science. 1384;29(3):239-243.
15. Silva LF, Medes R. Combined exposure to noise and vibration and its effects on worker's hearing. Rev Saudi Publica 2005;39(1):9-17.

16. Tajik R, et al. The effects of Noise Pollution and Hearing of metal Workers in Arak. Tabibe Shargh journal. 1387;10(4):291-298.

17. Ferrite S, Santana V. Joint effect of smoking, noise exposure and age on hearing loss. Occup Med (Lond). 2005;55(1):48-53.

18. Parvizpor D, Akbarekhanzade F. Study of the hearing loss and environment noise in metal industry worker. Journal of Medical Council Of Islamc Republic Of Iran. 1981;2(8):93-99. 